NASA/TM-2006-214037

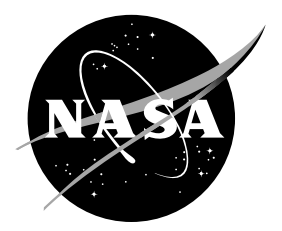

\title{
Micro-Energy Rates for Damage Tolerance and Durability of Composite Structures
}

Christos C. Chamis

Glenn Research Center, Cleveland, Ohio

Levon Minnetyan

Clarkson University, Potsdam, New York 
Since its founding, NASA has been dedicated to the advancement of aeronautics and space science. The NASA Scientific and Technical Information (STI) Program Office plays a key part in helping NASA maintain this important role.

The NASA STI Program Office is operated by Langley Research Center, the Lead Center for NASA's scientific and technical information. The NASA STI Program Office provides access to the NASA STI Database, the largest collection of aeronautical and space science STI in the world. The Program Office is also NASA's institutional mechanism for disseminating the results of its research and development activities. These results are published by NASA in the NASA STI Report Series, which includes the following report types:

- $\quad$ TECHNICAL PUBLICATION. Reports of completed research or a major significant phase of research that present the results of NASA programs and include extensive data or theoretical analysis. Includes compilations of significant scientific and technical data and information deemed to be of continuing reference value. NASA's counterpart of peerreviewed formal professional papers but has less stringent limitations on manuscript length and extent of graphic presentations.

- TECHNICAL MEMORANDUM. Scientific and technical findings that are preliminary or of specialized interest, e.g., quick release reports, working papers, and bibliographies that contain minimal annotation. Does not contain extensive analysis.

- CONTRACTOR REPORT. Scientific and technical findings by NASA-sponsored contractors and grantees.
- CONFERENCE PUBLICATION. Collected papers from scientific and technical conferences, symposia, seminars, or other meetings sponsored or cosponsored by NASA.

- SPECIAL PUBLICATION. Scientific, technical, or historical information from NASA programs, projects, and missions, often concerned with subjects having substantial public interest.

- TECHNICAL TRANSLATION. Englishlanguage translations of foreign scientific and technical material pertinent to NASA's mission.

Specialized services that complement the STI Program Office's diverse offerings include creating custom thesauri, building customized databases, organizing and publishing research results ... even providing videos.

For more information about the NASA STI Program Office, see the following:

- Access the NASA STI Program Home Page at http://www.sti.nasa.gov

- E-mail your question via the Internet to help@sti.nasa.gov

- Fax your question to the NASA Access Help Desk at 301-621-0134

- Telephone the NASA Access Help Desk at 301-621-0390

- Write to:

NASA Access Help Desk

NASA Center for AeroSpace Information 7121 Standard Drive

Hanover, MD 21076 
NASA/TM-2006-214037

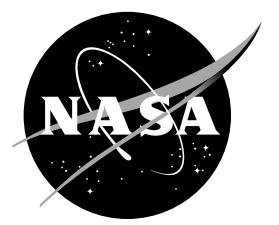

\section{Micro-Energy Rates for Damage Tolerance and Durability of Composite Structures}

Christos C. Chamis

Glenn Research Center, Cleveland, Ohio

Levon Minnetyan

Clarkson University, Potsdam, New York

Prepared for the

16th European Conference on Fracture

cosponsored by ASTM, JSEM, SMS, BSSM, AIAS, SEM, and EURASEM

Alexandroupolis, Greece, July 3-7, 2006

National Aeronautics and

Space Administration

Glenn Research Center 
This work was sponsored by the Fundamental Aeronautics Program at the NASA Glenn Research Center.

Available from

NASA Center for Aerospace Information 7121 Standard Drive

Hanover, MD 21076
National Technical Information Service 5285 Port Royal Road Springfield, VA 22100

Available electronically at http:/ /gltrs.grc.nasa.gov 


\title{
Micro-Energy Rates for Damage Tolerance and Durability of Composite Structures
}

\author{
Christos C. Chamis \\ National Aeronautics and Space Administration \\ Glenn Research Center \\ Cleveland, Ohio 44135 \\ Levon Minnetyan \\ Clarkson University \\ Department of Civil Engineering \\ Potsdam, New York 13699
}

\begin{abstract}
In this paper, the adhesive bond strength of lap-jointed graphite/aluminum composites is examined by computational simulation. Computed micro-stress level energy release rates are used to identify the damage mechanisms associated with the corresponding acoustic emission (AE) signals. Computed damage regions are similarly correlated with ultrasonically scanned damage regions. Results show that computational simulation can be used with suitable NDE methods for credible in-service monitoring of composites.
\end{abstract}

\section{Introduction}

For effective structural health monitoring, it is important to quantify damage tolerance of a candidate structure. Since continuous fiber composites are able to arrest cracks and prevent self-similar crack propagation, composite structures have received a great deal of consideration for design with emphasis on damage tolerance. However, a number of design parameters such as fiber orientation patterns, choices of constituent material combinations, ply drops and hybridization, result in complex design options for composite structures. Thus, it is necessary to evaluate damage initiation in a composite structure and its fracture propagation characteristics for achieving a rational damage tolerant design.

Compared with homogeneous materials, damage initiation and progression characteristics of fiber composites are much more complicated. Composite structures often contain some pre-existing or induced flaws in matrix and fibers after fabrication of composites. At lower stresses, matrix is likely to be cracked because of flaw-induced stress concentrations and cause the matrix flaws to propagate across the composite. With the use of established material modeling and finite element models, and considering the influence of local defects, through-the-thickness cracks and residual stresses, computational simulations have made it possible to evaluate the details of progressive damage and fracture in composite structures. In a computational simulation, damage evolution quantifier such as the damage volume, exhausted damage energy, and the damage energy release rate (DERR) are used to quantify the structural damage tolerance at different stages of degradation. Low DERR levels usually indicate that degradation takes place with minor resistance by the structure. Structural resistance to damage propagation is often dependent on structural geometry and boundary conditions as well as the applied loading and the state of stress.

In certain cases such as the room temperature behavior of composites designed for high-temperature applications, internal damage initiated as microcracks in the matrix become enlarged to be externally 
visible. Thus, matrix cracking and its effect on damage propagation/damage tolerance need be evaluated. Some simulations (refs. 1 and 2) have been successful in predicting damage tolerance and failure load of composite structure by considering ply stresses and the corresponding stress limits for matrix crack growth. In this paper, lap-jointed composite specimens subjected to uniaxial tension are investigated. Damage initiation, growth, accumulation, and propagation to fracture are studied. Since the complete evaluation of ply and subply level damage/fracture processes is the fundamental premise of computational simulation, a microstress level damage index is added for the identification and tracking of subply level damage processes. Computed damage regions are similarly correlated with ultrasonically scanned damage regions. Simulation is validated by comparison with test data from acoustic ultrasonic (AU) testing. Results show that computational simulation can be used with suitable NDE methods for credible inservice monitoring of composites.

\section{Methodology}

Computational simulation is implemented via integrating three modules: (1) composite mechanics, (2) finite element analysis, and (3) damage progression tracking. The composite mechanics module (ref. 3) is designed to analyze fiber composite structures with an updated composite mechanics theory. Its main function is to calculate ply and composite properties of laminates from the fiber and matrix constituent characteristics and the composite layup. Additionally, it determines the composite structural response and ply stresses from the FEM analysis results. In simulation, the composite mechanics module is called before and after each finite element analysis.

The finite element analysis module is able to process linear and nonlinear static and dynamic analysis. Four-node anisotropic thick shell elements are usually used to model laminated composites (ref. 4). The finite element analysis module accepts laminate properties from the composite mechanics module and performs the structural analysis at each load increment. After structural analysis, the computed generalized node stress resultants and deformations are provided to the composite mechanics module. The composite mechanics module computes the developed ply stresses for each ply and checks for ply failure modes at each node. Failure criteria applied to detect ply failures are based on the maximum stress and modified distortion energy (MDE) criteria for combined stress effects (ref. 3).

The overall evaluation of composite structural durability is carried out in the damage progression module (ref. 2) that keeps track of composite degradation for the entire structure. The damage progression module relies on the composite mechanics module for composite micromechanics, macromechanics and laminate analysis, and calls the finite element analysis module for global structural analysis. If excessive damage is detected, the incremental loads are reduced and the analysis is restarted from the previous equilibrium stage. Otherwise, if the increment of loads is acceptable, another finite element analysis is performed but the constitutive properties and the finite element mesh are updated to account for the damage and deformations from the last simulation. Simulation is stopped when global structural fracture is predicted.

\section{Method of Simulation}

The matrix in orthotropic composite plies is divided into two parts: regions A and B. Region A represents the area in which stress concentrations induced by the interaction of matrix and fiber do not create any effect in matrix. Region B represents the interaction zone between fiber and matrix. Figure 1 shows the details of regional subdivision in transverse and normal directions of a composite ply with square array packing. 


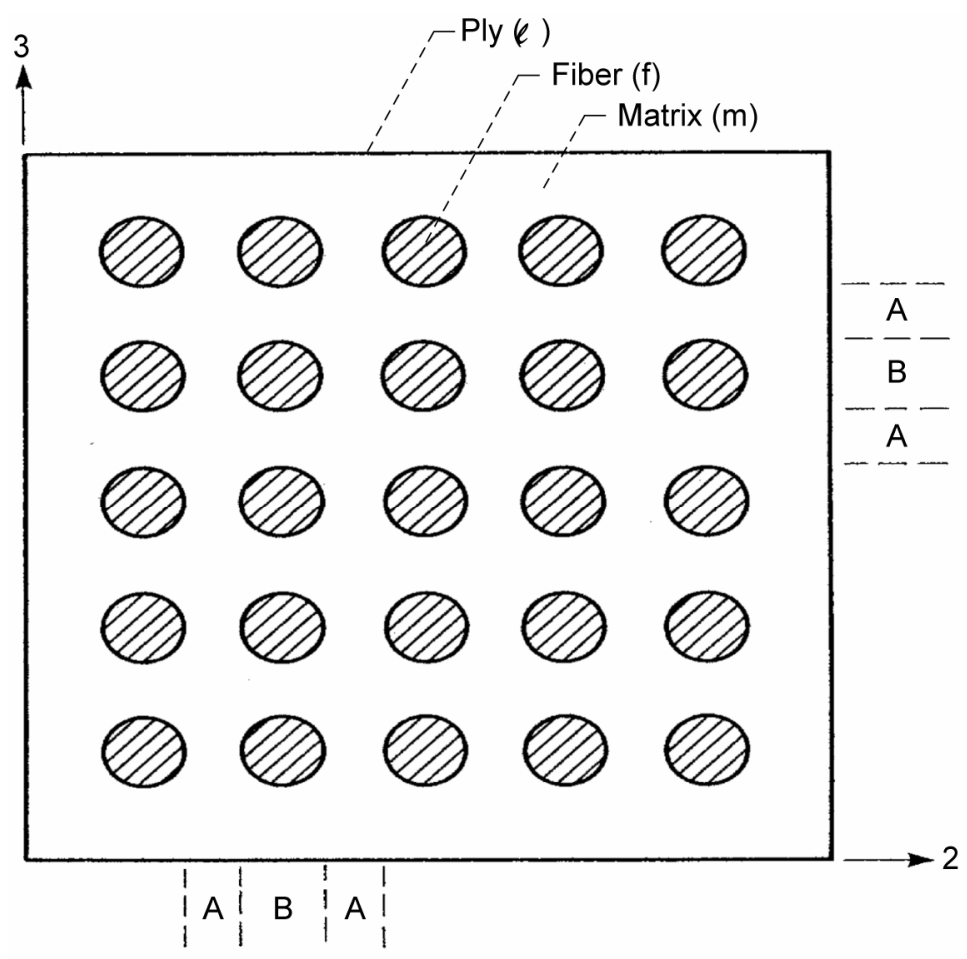

Figure 1.-Definitions of regions for ply microstress calculations.

Considering the behavior of longitudinal stress $\sigma_{l 11}$, transverse stress $\sigma_{l 22}$, in-plane shear stress $\sigma_{l 12}$, out-of plane shear stress $\sigma_{123}$, temperature gradient $\Delta \mathrm{T}_{l}$, and moisture $\mathrm{M}_{l}$, Murthy and Chamis (ref. 3) present the complete set of equations for evaluating ply microstresses in regions A and B. For example, ply microstresses due to $\sigma_{l 11}$ are given by:

$$
\begin{gathered}
\sigma_{m 11}=\left(E_{m} / E_{l 11}\right) \sigma_{l 11} \\
\sigma_{f 11}=\left(E_{f 11} / E_{l 11}\right) \sigma_{l 11} \\
\sigma_{m 22}^{(A)}=\sigma_{m 33}^{(A)}=\left(v_{m}-v_{l 12}\right)\left(E_{m} / E_{l 11}\right) \sigma_{l 11} \\
\sigma_{m 22}^{(B)}=\sigma_{m 33}^{(B)}=\sigma_{f 22}^{(B)}=\sigma_{f 33}^{(B)}=-\frac{1-\sqrt{k_{f}}}{k_{f}} \sigma_{l 11}
\end{gathered}
$$

in which $\sigma_{m 11}$ is the matrix longitudinal stress, $\sigma_{f 11}$ is the fiber longitudinal stress, $\sigma_{m 22}^{(A)}$ is the matrix transverse stress in region A, and $\sigma_{m 22}^{(B)}$ is the matrix transverse stress in region B. If the ply is subject to combined stresses, its microstresses are obtained by simply superimposing results of all corresponding stress components. Ply transverse fractures usually begin in region B due to the elevated stress levels from stress concentration. Microstress level damage tracking is able to quantify the type of damage in the matrix by comparison of microstresses with constituent stress limits. A microstress damage index is defined as a binary number with 14 bits in the damage progression module.

\section{Simulation Results and Discussion}

In this paper, two unidirectional graphite/aluminum composite plates (fig. 2) with single lap joint under uniaxial tension are used to demonstrate the use of microstress damage index in computational simulation. The specimen has a length of $\mathrm{L}=76.2 \mathrm{~mm}(3 \mathrm{in}$.), a width of $\mathrm{W}=19.05 \mathrm{~mm}(0.75 \mathrm{in}$.) and a 


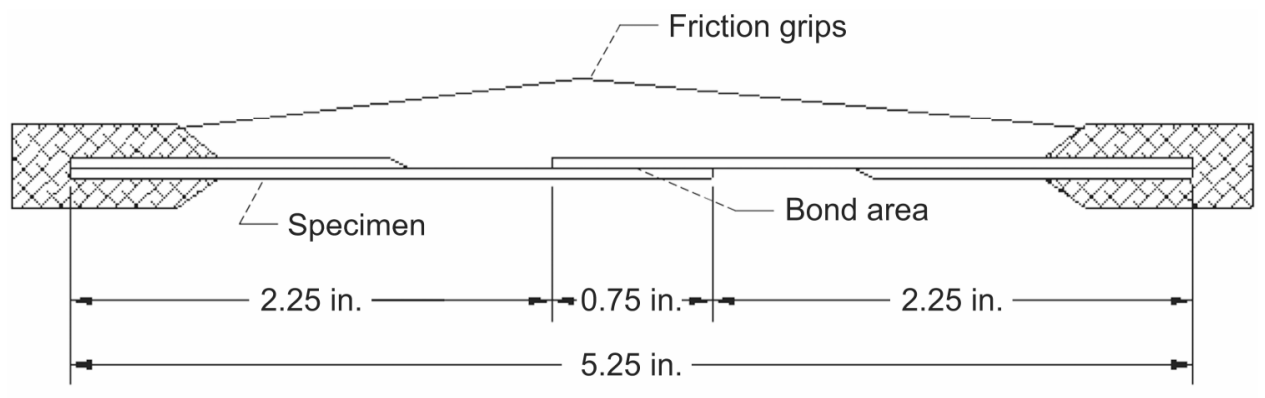

Figure 2.-Testing setup for adhesive bonded specimen.

thickness of $\mathrm{H}=1.27 \mathrm{~mm}(0.05$ in.). The fiber volume ratio is $\mathrm{Vf}=0.60$ and the void volume ratio is $\mathrm{Vv}_{\mathrm{v}}=0.01$. The specimens are bonded with adhesive to produce a bond area of 0.75 by $0.75 \mathrm{in}$. The first adhesive type is an epoxy resin and the other is a graphite/epoxy prepreg tape. The specimen is assumed to be dry with zero moisture content. Additionally, two metal plates with dimensions of 2 by 0.75 in. are also bonded to the specimens with epoxy resin (fig. 2). The fiber and matrix properties used for computational simulation are given in tables 1 and 2 .

The finite element model as shown in figure 3 has 451 nodes and 360 Mindlin type rectangular elements. To represent the test setup described by Quattlebaum (ref. 5), nodes along the end of the specimen are restrained against translation to model the fixed boundary and nodes at the end of another specimen are constrained only moveable in the longitudinal direction. Axial tension load is applied at the moveable end. Moreover, nodes along the moveable end are tied by duplicate node constraints to enforce the uniform displacement of the clamped loaded edge. Computational simulation indicated a damage initiation load of $4555.06 \mathrm{~N}(1024 \mathrm{lb})$ for the lap joint with epoxy resin. The damage initiation mode was by ply longitudinal tensile failures in the $0^{\circ} \mathrm{ply}$ and the microstress damage indexes are activated for the SM1A(+), SM2A(+), SM2B(-), SM3A(+), SM3B(-), SM12A, SM12B, SM13A, and SM23A microfailure modes. The locations of damage initiation were at the lap joint area. After damage initiation, longitudinal tensile failures spread to the interface between lap joint and composite plate as the applied load reached $7584.35 \mathrm{~N}(1705 \mathrm{lb})$. Then, longitudinal tensile failures continuously spread at the lap joint with the load increasing to $7691 \mathrm{~N}(1729 \mathrm{lb})$. The microstress damage indexes were also activated for the SM1A(+), SM2A(+), SM2B(-), SM3A(+), SM3B(-), SM12A, SM12B, SM13A, and SM23A microfailure modes. Thereafter, longitudinal tensile failures developed at the lap joint and the interface between lap joint and the composite plate as the load increased. The lap joint continued to fracture rapidly and broke under the $44.096 \mathrm{kN}$ (9913 lb) loading. Computational simulation indicated that substantial adhesive damage resulted in failure of the lap joint.

For the lap joint with graphite/epoxy prepreg tape as its adhesive, the damage initiation load was $36.45 \mathrm{kN}(8193 \mathrm{lb})$ by ply longitudinal tensile failures in the $0^{\circ}$ ply. The damage initiation took place at the edges of the lap joint adjacent to the composite plate. The microstress damage indices were activated for SM1A(+), SM2A(+), SM2B(-), SM3A(+), SM3B(-), SM12A, SM12B, SM13A, and SM23A microfailure modes. After damage initiation, longitudinal tensile failures spread to plies of the specimen as the applied load reached $42.52 \mathrm{kN}(9558 \mathrm{lb})$. Subsequently, damage growth was limited mainly to the first two plies of interface between the edge of lap joint and the composite plate until the load was increased to $44.53 \mathrm{kN}(10010 \mathrm{lb})$. At $44.75 \mathrm{kN}(10060 \mathrm{lb})$, longitudinal tensile failures spread to plies around the edge of lap joint. The microstress damage indices were activated for SM1A(+), SM2A(+), SM2B(-), SM3A(+), SM3B(-), SM12A, SM12B, SM13A, and SM23A microfailure modes. With increasing load, fracture continued to develop at the edges of the lap joint and the specimen broke under the $52.49 \mathrm{kN}(11800 \mathrm{lb})$ loading. Similar to the simulation for the lap joint bonded with epoxy resin. 
TABLE 1.-AS-4 FIBER PROPERTIES

\begin{tabular}{|l|l|}
\hline \multicolumn{1}{|c|}{ Nomenclature } & \multicolumn{1}{c|}{ Values } \\
\hline Number of fibers per end & 10000 \\
\hline Fiber diameter & $0.00508 \mathrm{~mm}\left(0.200 \times 10^{-3} \mathrm{in}.\right)$ \\
\hline Fiber density & $4.04 \times 10^{-7} \mathrm{Kg} / \mathrm{m}^{3}\left(0.063 \mathrm{lb} / \mathrm{in} .{ }^{3}\right)$ \\
\hline Longitudinal normal modulus & $226.84 \mathrm{GPa}\left(3.29 \times 10^{7} \mathrm{psi}\right)$ \\
\hline Transverse normal modulus & $13.72 \mathrm{GPa}\left(0.199 \times 10^{7} \mathrm{psi}\right)$ \\
\hline Poisson's ratio $\left(v_{12}\right)$ & 0.200 \\
\hline Poisson's ratio $\left(v_{23}\right)$ & 0.250 \\
\hline Shear modulus $\left(\mathrm{G}_{12}\right)$ & $13.79 \mathrm{GPa}\left(0.20 \times 10^{7} \mathrm{psi}\right)$ \\
\hline Shear modulus $\left(\mathrm{G}_{23}\right)$ & $6.89 \mathrm{GPa}\left(0.10 \times 10^{7} \mathrm{psi}\right)$ \\
\hline Longitudinal thermal expansion coefficient & $1.0 \times 10^{-6} /{ }^{\circ} \mathrm{C}\left(-0.55 \times 10^{-6} /{ }^{\circ} \mathrm{F}\right)$ \\
\hline Transverse thermal expansion coefficient & $1.0 \times 10^{-6} /{ }^{\circ} \mathrm{C}\left(0.56 \times 10^{-6} /{ }^{\circ} \mathrm{F}\right)$ \\
\hline Longitudinal heat conductivity & $301 \mathrm{~kJ}-\mathrm{m} / \mathrm{hr} / \mathrm{m}^{2} /{ }^{\circ} \mathrm{C}\left(4.03 \mathrm{BTU}-\mathrm{in} . / \mathrm{hr} / \mathrm{in} .{ }^{2} /{ }^{\circ} \mathrm{F}\right)$ \\
\hline Transverse heat conductivity & $30.1 \mathrm{~kJ}-\mathrm{m} / \mathrm{hr} / \mathrm{m}^{2} /{ }^{\circ} \mathrm{C}\left(0.403 \mathrm{BTU}-\mathrm{in} . / \mathrm{hr} / \mathrm{in} .{ }^{2} /{ }^{\circ} \mathrm{F}\right)$ \\
\hline Heat capacity & $0.712 \mathrm{~kJ} / \mathrm{kg} /{ }^{\circ} \mathrm{C}\left(0.17 \mathrm{BTU} / \mathrm{lb} /{ }^{\circ} \mathrm{F}\right)$ \\
\hline Tensile strength & $3.72 \mathrm{GPa}(540 \mathrm{ksi})$ \\
\hline Compressive strength & $3.35 \mathrm{GPa}(486 \mathrm{ksi})$ \\
\hline
\end{tabular}

TABLE 2.--EPOXY MATRIX PROPERTIES

\begin{tabular}{|l|l|}
\hline \multicolumn{1}{|c|}{ Nomenclature } & \multicolumn{1}{c|}{ Values } \\
\hline Matrix density & $3.30 \times 10^{-7} \mathrm{Kg} / \mathrm{m}^{3}\left(0.0443 \mathrm{lb} / \mathrm{in} .^{3}\right)$ \\
\hline Normal modulus & $3.45 \mathrm{GPa}(500 \mathrm{ksi})$ \\
\hline Poisson's ratio & 0.35 \\
\hline Coefficient of thermal expansion & $0.77 \times 10^{-4} /{ }^{\circ} \mathrm{C}\left(0.428 \times 10^{-4} /{ }^{\circ} \mathrm{F}\right)$ \\
\hline Heat conductivity & $0.648 \mathrm{~kJ}-\mathrm{m} / \mathrm{hr} / \mathrm{m}^{2} /{ }^{\circ} \mathrm{C}\left(0.868 \times 10^{-2} \mathrm{BTU}-\mathrm{in} / \mathrm{hr} / \mathrm{in} .{ }^{2} /{ }^{\circ} \mathrm{F}\right)$ \\
\hline Heat capacity & $1.047 \mathrm{KJ} / \mathrm{Kg} /{ }^{\circ} \mathrm{C}\left(0.25 \mathrm{BTU} / \mathrm{lb} /{ }^{\circ} \mathrm{F}\right)$ \\
\hline Tensile strength & $68.99 \mathrm{MPa}(10.0 \mathrm{ksi})$ \\
\hline Compressive strength & $241.59 \mathrm{MPa}(35.0 \mathrm{ksi})$ \\
\hline Shear strength & $89.7 \mathrm{MPa}(13.0 \mathrm{ksi})$ \\
\hline Allowable tensile strain & 0.02 \\
\hline Allowable compressive strain & 0.05 \\
\hline Allowable shear strain & 0.045 \\
\hline Allowable torsional strain & 0.045 \\
\hline Void conductivity & $16.8 \mathrm{~J}-\mathrm{m} / \mathrm{hr} / \mathrm{m}^{2} /{ }^{\circ} \mathrm{C}\left(0.225 \mathrm{BTU}-\mathrm{in} . / \mathrm{hr} / \mathrm{in} .{ }^{2} /{ }^{\circ} \mathrm{F}\right)$ \\
\hline Glass transition temperature & $216^{\circ} \mathrm{C}\left(420{ }^{\circ} \mathrm{F}\right)$ \\
\hline
\end{tabular}

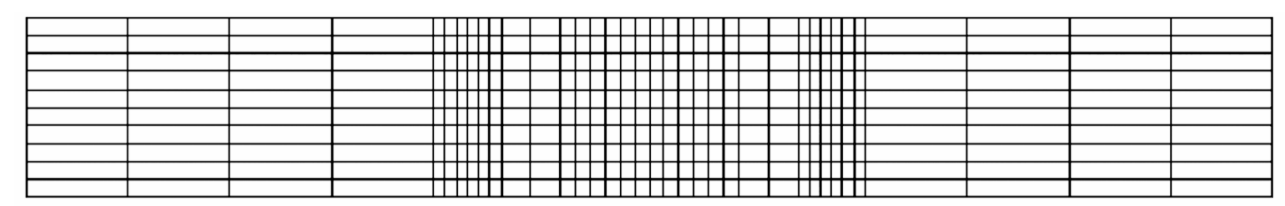

Figure 3.-Finite element model of composite specimen. 
Figure 4 shows the relation between displacement and loading for lap joint with two different adhesives. It indicates the bonded strength of lap joint with graphite/epoxy prepreg tape is approximately 1.19 times higher than that of the epoxy bonded joint, a little lower than experimental results by Quattlebaum (ref. 5). This is due to some difference in the material properties in simulation and experiment. On the other hand, the apparent linear relationship between the load and displacement depicted in figure 4 is not able to reflect the presence of internal damage initiation and growth processes.

For epoxy and graphite/epoxy prepreg tape bonded specimens, figures 5(a) and (b) compare the change of microstress energy component SM1A $(+)$ with increasing displacement. It shows that the peak of SM1A(+) for graphite/epoxy prepreg tape is quite later and higher than that of epoxy. This means cracking in region A for epoxy bonded joint is earlier than prepreg bonded joint. The difference in the damage energy amplitudes indicate that the prepreg bonded joint has a much higher energy of SM1A $(+)$ damage.

Figures 5(c) and (d) show the microstress energy component SM2A(+) as a function of displacement. From the plots, it is obvious that prepreg specimen can withstand higher transverse tensile stress in large displacement than epoxy specimen. It reflects that there is greater resistance against crack initiation in matrix for prepreg specimen.

Figures 5(e) and (f) show the relation of microstress energy component SM2B(-) versus displacement. It is observed that the stress required to cause transverse debonding at the fiber-matrix interface for prepreg specimen is larger than that for epoxy specimen. The bond strength for epoxy specimen is not as strong as that for prepreg specimen. This is mainly due to the fiber bridging effects that impede crack propagation in the prepreg-bonded specimen.

Figures 5(g) and (h) plot microstress energy component SM13A versus displacement. In the graph, the shear stress (out of plane) in region A for prepreg bonded joint is higher than that for epoxy bonded joint. It shows that there exist bridging fibers in prepreg specimen.

Quattlebaum (ref. 5) presented the acoustic activity data obtained from epoxy resin and prepreg specimens with the same configuration as the computational simulation. Direct comparison of the acoustic emission signals with computed microstress level damage energies was not possible because the computed damage energy values had much fewer points than the experimentally measured acoustic emission data. The apparent reason for the mismatch of refinement between experimental and computational values is that microstress level damage tracking is not sufficient to capture the acoustic emission data from NDE testing. For correlation of current microstress level damage energy tracking with Quattlebaum's test data, we used a curve fitting software, TableCurve2D v5 2000 (ref. 6), to find the fitted curve that envelops acoustic signals.

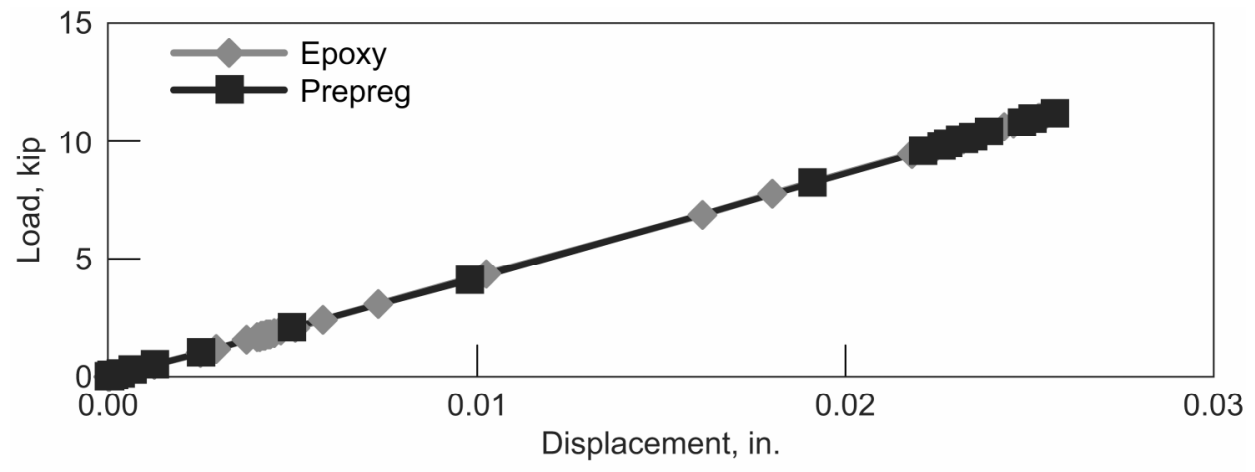

Figure 4.-Displacement with loading for coupon. 



Figure 5.-Displacement with microstress level damage energy components. (a) Displacement with $\mathrm{SM} 1 \mathrm{~A}(+)$ for epoxy resin bonded joints. (b) Displacement with SM1A(+) for graphite/epoxy prepreg bonded joints. (c) Displacement with SM2A(+) for epoxy resin bonded joints. (d) Displacement with $\mathrm{SM} 2 \mathrm{~A}(+)$ for graphite/epoxy prepreg bonded joints. (e) Displacement with SM2B(-) for epoxy resin bonded joints. (f) Displacement with SM2B(-) for graphite/epoxy prepreg bonded joints. (g) Displacement with SM13A for epoxy resin bonded joints. (h) Displacement with SM13A for graphite/epoxy prepreg bonded joints. 

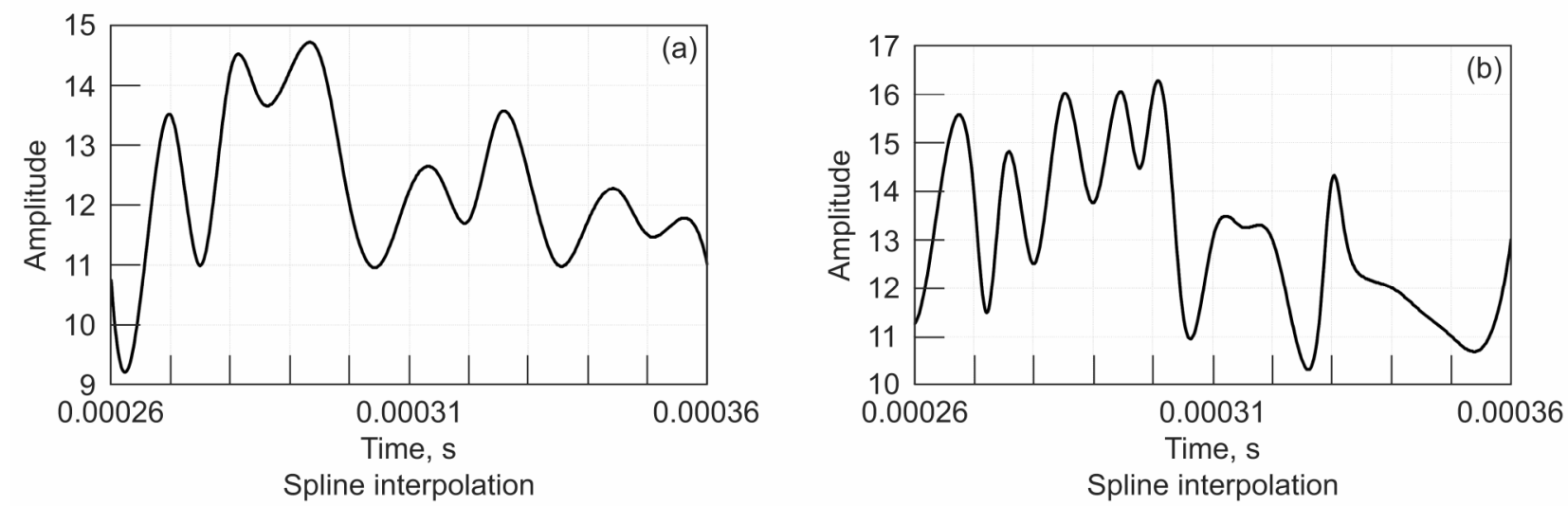

Figure 6.-Energy envelope of acoustic emission signals for bonded specimens. (a) Epoxy resin. (b) Prepreg.



Figure 7.-Damage with damage energy for coupon.

Figure 6(a) shows the envelope curve for epoxy resin bonded specimen and figure 6(b) plots the envelope curve for prepreg bonded specimen. Experimental acoustic emission levels are marked with slight ticks as points through which curves are drawn in figures 6(a) and (b). The area under the envelope represents the total damage energy detected by the acoustic emission during the period monitored. Thus, we can correlate the microstress damage energy through computational simulation with the relative total damage energies represented by the envelope areas. The envelope area in figure 6 (a) is $1.22986 \times 10^{-3}$ and that in figure $6(\mathrm{~b})$ is $1.30145 \times 10^{-3}$. The ratio of the energies from figure $6(\mathrm{~b})$ to that of figure $6(\mathrm{a})$ is 1.058. Comparatively, the ratio of simulation results for damage energy shown in figure 7 is 1.168 , which is 10 percent higher than the ratio computed from the NDE test results.

\section{Conclusions}

The failure patterns of the investigated fiber composite specimens and the available computational simulation results are found that:

1. Microstress level damage tracking is able to evaluate the bond strength and monitor adhesive yielding.

2. Microstress level computational simulation provides the details of damage initiation, growth, and subsequent fracture in composites. It represents a new approach for investigating damage mechanisms of composites. 
3. Computational simulation shows a good correlation with AU signals in the cumulative sense.

4. The demonstrated procedure is flexible and applicable to all types of constituent materials, structural geometry, and loading. Hybrid composites, as well as laminated, stitched, woven, and braided composites can be simulated.

5. Computational simulation, with the use of established composite mechanics and finite element models can be used to predict the influence of microstresses, as well as loading and material properties on the durability of composite structures.

\section{References}

1. Zhang, H., Minnetyan, L., and Chamis, C.C. (2001), "Microstress Level Damage Evolution in Composite Structures," 46th International SAMPE Symposium, Long Beach, CA.

2. Minnetyan, L., Murthy, P.L.N., and Chamis, C.C. (1990), "Composite Structure Global Fracture Toughness via Computational Simulation," Computers and Structures, 37, 2, pp. 175-180.

3. Murthy, P.L.N., and Chamis, C.C. (1986), "Integrated Composite Analyzer (ICAN): Users and Programmers Manual," TP-2515.

4. Nakazawa, S., Dias, J.B., and Spiegel, M.S. (1987), "MHOST Users' Manual," prepared for NASA Lewis Research Center by MARC Analysis Research Corporation.

5. Quattlebaum, G.J., and Raju, P.K. (1997), "Nondestructive Evaluation of Graphite/Aluminum Composites Using Acousto-Ultrasonics," Proceedings of the ASME Noise Control and Acoustics Division.

6. TableCurve2D v5 (2000), AISN software. 


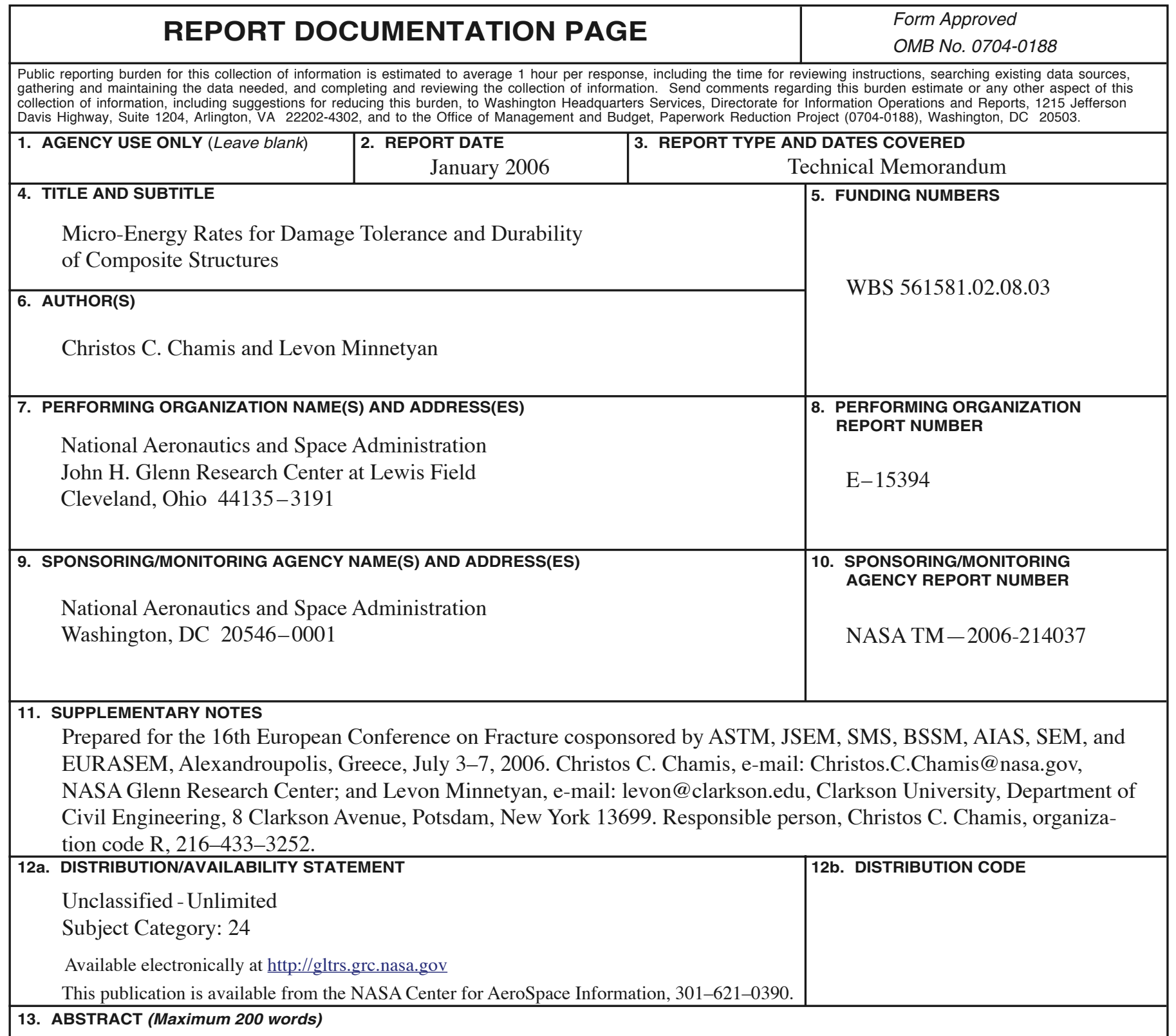

In this paper, the adhesive bond strength of lap-jointed graphite/aluminum composites is examined by computational simulation. Computed micro-stress level energy release rates are used to identify the damage mechanisms associated with the corresponding acoustic emission (AE) signals. Computed damage regions are similarly correlated with ultrasonically scanned damage regions. Results show that computational simulation can be used with suitable NDE methods for credible in-service monitoring of composites.

\begin{tabular}{|c|c|c|c|}
\hline \multicolumn{3}{|l|}{ 14. SUBJECT TERMS } & \multirow{2}{*}{\begin{tabular}{|c|} 
15. NUMBER OF PAGES \\
15
\end{tabular}} \\
\hline \multicolumn{3}{|c|}{ Acoustic emission; Joints; Microstresses; Damage mechanisms } & \\
\hline $\begin{array}{l}\text { 17. SECURITY CLASSIFICATION } \\
\text { OF REPORT }\end{array}$ & $\begin{array}{l}\text { 18. SECURITY CLASSIFICATION } \\
\text { OF THIS PAGE }\end{array}$ & $\begin{array}{l}\text { 19. SECURITY CLASSIFICATION } \\
\text { OF ABSTRACT }\end{array}$ & 20. LIMITATION OF ABSTRACT \\
\hline Unclassified & Unclassified & Unclassified & \\
\hline
\end{tabular}



